\title{
Vorwort des Herausgebers der 5. Auflage
}

Trotz zunehmender Bedeutung physikalisch-chemischer Analysenmethoden, vor allem der Spektralanalyse, wird man auf den naßchemischen Weg zur Ausführung qualitativer Analysen nicht verzichten können. Das gilt vor allem beim Nachweis von Anionen und beim Vorliegen von Einzelproblemen sowie für jene Institute und Laboratorien, die über kein Spektralgerät verfügen.

Die qualitative Schnellanalyse noch Charlot verzichtet auf oinen systematischen Trennungsgang und gestattet es, einzelne Ionen im Gemisch schnell und sicher zu erkennen.

Die vorliegende 5. Auflage hält sich an das bewährte Konzept der vorangegangenen. Es sind einige Verbesserungen, so zur Bestimmung des Uranylions und des Chloridions, und Überarbeitungen vorgenommen worden.

Aaohen, April 1969

Annelore Köster-Pflugmacher 